\title{
NASOSINUSAL MENINGIOMA. A CASE REPORT
}

\section{Serban V.G. BERTESTEANU ${ }^{1,2}$, Paula L. BEJENARU ${ }^{1 凶}$, Mihnea CONDEESCU-COJOCARITA ${ }^{1,2}$, Gloria S. MUNTEANU ${ }^{1}$, Catrinel B. SIMION-ANTONIE ${ }^{1}$, Anca CIRSTEA $^{1}$, Raluca GRIGORE ${ }^{1,2}$}

${ }^{1}$ ENT Department, Coltea Clinical Hospital, Bucharest, Romania

${ }^{2}$ University of Medicine and Pharmacy „Carol Davila“, Bucharest, Romania

Received 02 May 2020, Accepted 13 May 2020

https://doi.org/10.31688/ABMU.2020.55.2.19

\section{Abstract}

Introduction. Meningiomas are benign tumours of the arachnoid layer and although relatively frequent they have an intracranial development, implications of the visceral cranium or the neck are rare.

Case presentation. We present the case of a 67-year-old male with an intracranial meningioma, with recurrences in the extra cranial area. We focused on clinical presentation, imaging studies and treatment options in this kind of tumour. Extra cranial meningiomas, primary or secondary, are rare and a sinonasal type should always be considered that it may be an extension of an intracranial tumour. The recurrence rate is moderate and outcome is good, but a missed follow-up may lead to unfavourable consequences. Treatment options may vary from „watch and wait" to surgery - transcranial and endoscopic approaches, combined techniques - and even radiotherapy, depending on the site and extension.

Conclusions. Endoscopic endonasal surgery may be a safe and effective way of treatment for skull base tumours, although it requires advanced techniques and a good knowledge of reconstruction of dura and skull base defects. There are also limitations, that can be surpassed with a combined approach.

\section{RÉSUMÉ}

Le méningiome endo-nasal - présentation de cas

Introduction. Les méningiomes sont des tumeurs bénignes de la couche arachnoïdienne et bien qu'ils soient relativement fréquents ont un développement intracrânien, les implications extra crâniennes ou du cou étant rares.

Rapport du cas. Nous présentons le cas d'un homme de 67 ans, diagnostiqué avec un méningiome intracrânien avec récidives dans la zone extra-crânienne. Nous nous sommes concentrés sur la présentation clinique, les études d'imagerie et les options de traitement dans ce type de tumeur. Les méningiomes extra-crâniens, primaires ou secondaires sont rares. Dans le cas d'un méningiome sino-nasal jusqu'à la preuve du contraire, nous devons considérer qu'il peut s'agir d'une extension d'une tumeur intracrânienne. Le taux de récidive est modéré et les résultats sont bons, mais un suivi raté peut entrainer des conséquences défavorables. Les options de traitement peuvent varier de la surveillance et de l'attente à la chirurgie - approches transcrâniennes et endoscopiques, techniques combinées - et même la radiothérapie, selon le site et l'extension.

Conclusions. La chirurgie endo-nasale endoscopique peut devenir un moyen sûr et efficace de traitement des 
Keywords: meningioma, skull base, endoscopic surgery.

\section{INTRODUCTION}

Skull base tumours are particularly difficult to diagnose and treat, considering the noble structures that they may involve. With modern technology development, solutions have been found and multidisciplinary teams now can manage these cases with less morbidities.

The meninges consist of three protective layers: the dura mater, arachnoid and pia mater. The cells that line the arachnoid villi are the cells of origin for meningioma. Meningiomas are benign, but locally aggressive tumours, and represent $18 \%$ of all intracranial tumours. They can develop in various anatomic sites: parasagittal region, falx, convexity, olfactory groove, tuberculum sellae, sphenoid ridge, petrous face (CPA), tentorium, lateral ventricle, clivus, and others ${ }^{1}$.

Meningiomas occur intracranial in $90 \%$ of the cases, $9 \%$ spinal, and 1\% ectopic ${ }^{2}$. Parasagittal and convexity are the most common cranial locations $(50 \%)^{2}$. Anterior skull base meningiomas are very frequent and they may be located mostly in tuberculum sellae, sphenoidal ridge, and olfactory groove ${ }^{2}$.

Extracranial meningiomas are rare, and may be divided into primary and secondary types, based on absence or presence of intracranial attachments. Primary extra cranial meningiomas are extremely rare entities, with less than 50 cases being reported in the literature; some of them may be a result of posttraumatic lesions or ectopic tissue $\mathrm{e}^{3-5}$.

\section{Case presentation}

We report the case of a 67-year-old male, who presented at the ENT Department of "Coltea“ Clinical Hospital, Bucharest, Romania, for unilateral - left - nasal obstruction, bilateral rhinorrhoea, sight difficulties (on left side), headaches and progressive left hearing loss. In 2011, he was diagnosed with a meningioma, that was resected. He presented, at that time, behavioural changes, headaches, fatigue and a syncope. The tumour was tumeurs de la base du crâne bien qu'elle nécessite de bonnes techniques, des moyens et des connaissances avancés pour la reconstruction de la dure-mère et des défauts de la base du crâne. L'approche combinée peut dépasser les limites de l'utilisation d'une seule technique.

Mots-clés: méningiome, base du crâne, chirurgie endoscopique.

a frontal-temporal meningioma $(5 / 5 / 6 \mathrm{~cm})$ with the origin point at the external sphenoidal crest, infratemporal fossa, cavernous sinus and near optic nerve, which was resected completely. The follow-up was good until 2014, when the patient had another intervention, with total resection, but with postsurgical complications: motor aphasia and pyramidal syndrome. There was no evidence of radiation exposure in his history, but he was a heavy smoker and a drinker. Furthermore, the follow-up missed and he requested an ENT evaluation based on the symptoms mentioned above. The patient signed the informed consent and voluntarily confirmed his willingness to participate in this study.

Clinical examination revealed postsurgical deformity, with substance loss in the left frontal-temporal region, scars, left exophthalmia, sensibility at palpation of the sinusal points, without oculomotors impairment, left mixed hearing loss. After the ophthalmology testing, loss of left visual field was diagnosed. Flexible endoscopy revealed a lobulated tumour, with complete obstruction of the left nasal fossa (Fig. 1-4), with origin in the lateral wall, extending to the rhino pharynx, and pressing the nasal septum.

Magnetic resonance imaging (MRI) studies showed left anterior frontal craniectomy, with left temporal fossa sequelae area and an $8 / 9 \mathrm{~cm}$ gadolinophilic tumour mass (Fig. 5-7). The tumour was enclosing the clivus, the apex of the temporal bone, the Turkish saddle, the cavernous sinuses, the sphenoid sinus, the optic nerve at the optic chiasm; it covered the left pterygoid fossa, nasopharynx and it bulged at the level of the infratemporal fossa, with the encasement of the intrapetrous and intra-cavernous segment of internal carotid artery that presented flow; finally, it had mass effect on the brainstem.

Although meningioma has good outcomes, in this case the treatment of an extensive recurrence with fibrotic postoperative changes at an advanced age would involve challenging complications and it would require a multidisciplinary team. The case was evaluated by the tumour board and the balance 

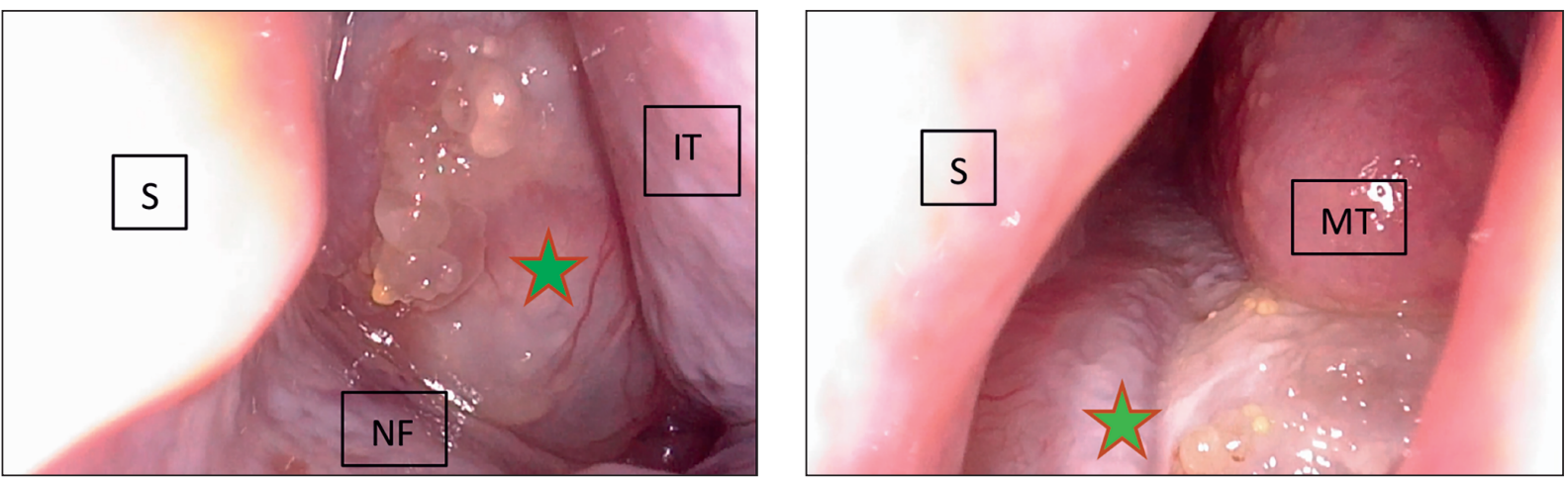

Fig. 1, 2. Left nasal fossa endoscopy
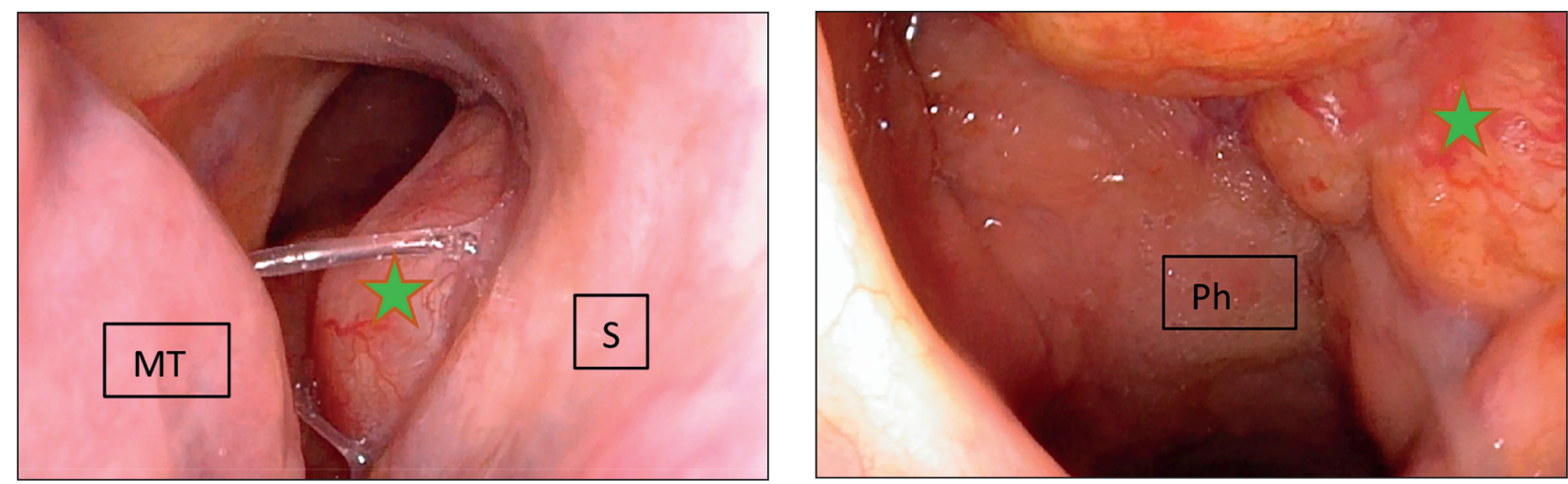

Fig. 3, 4. Right nasal fossa endoscopy and nasal pharynx.

$\mathrm{S}$ - septum, IT- inferior turbinate, MT - middle turbinate, $\mathrm{Ph}$ - pharynx, Star - tumour

of complication rate and poor prognosis guided the team to evaluate periodically the patient and treat only potential compressive emergencies. This is the case when curative intention should be well balanced with complications rate and prognosis. The unfavourable outcome may be due to lack of follow-up of a benign tumour which presents a relatively high grade of recurrence.

\section{Discussion}

The gross appearance of meningioma typically is that of a globular mass firmly adherent to the dura mater, with characteristic speckles scattered throughout the tumour, that correspond to the microscopic psammoma bodies. The tumour displaces, but does not invade adjacent neural tissue, and has a thin investing capsule. Meningiomas can invade bone without destruction, by extension along harversian canals. Adjacent bone is hyperostotic in $25 \%$ of cases ${ }^{1}$.

World Health Organization (WHO) system is directly linked to prognostic significance:

- Grade I (benign; 90\%): meningothelial, fibrous, transitional psammomatous, and angioplastic.
- Grade II (atypical; 7\%): choroid, clear cell, atypical with brain invasion.

- Grade III (anaplastic/malignant; 2\%): papillary, rhabdoid, anaplastic.

Relapse-free survival for grade I lesions is dependent on resection and grade II and III lesions are associated with approximately 12 and 3 years relapse-free survival, respectively ${ }^{1}$.

Meningiomas that involve the anterior skull base (olfactory groove and planum sphenoidal) are usually confined to the intracranial compartment. Extension into the sinuses is uncommon but does occur. Some of these tumours may be amendable to endoscopic surgery ${ }^{1}$.

Peak age at presentation is 40 - 60 years; females are more often affected - and there are some studies that may suggest a hormonal development. The incidence is increased by radiation, with increasing age, and by the presence of neurofibromatosis type $2^{2}$. Neurofibromatosis type 2 is characterized by the development of bilateral vestibular schwannomas and other intracranial and spinal tumours, that include schwannomas, meningiomas, gliomas, and ependymomas. In addition, patients may have posterior subcapsular lenticular opacities ${ }^{1}$. 


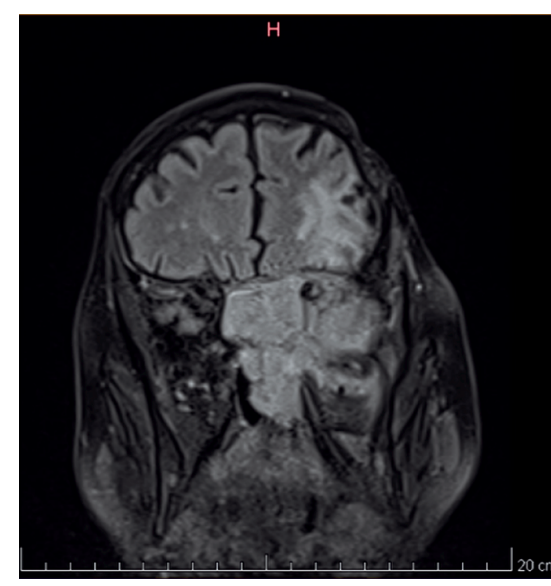

Fig. 5. MRI - T2 Coronal - Encasement of the optic nerve

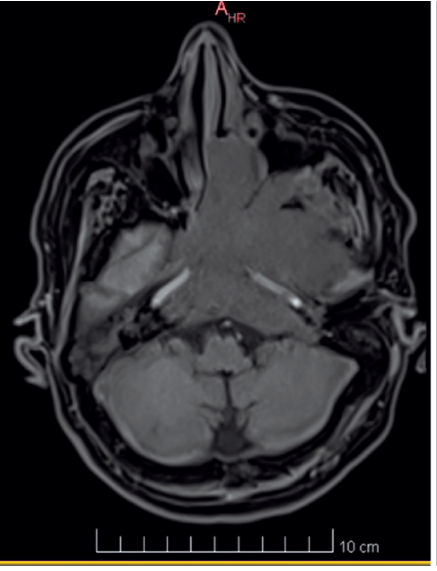

Fig. 6. MRI - T1 Axial Involvement of pterygopalatine fossa, infratemporal fossa, temporal bone apex with extension towards posterior skull base

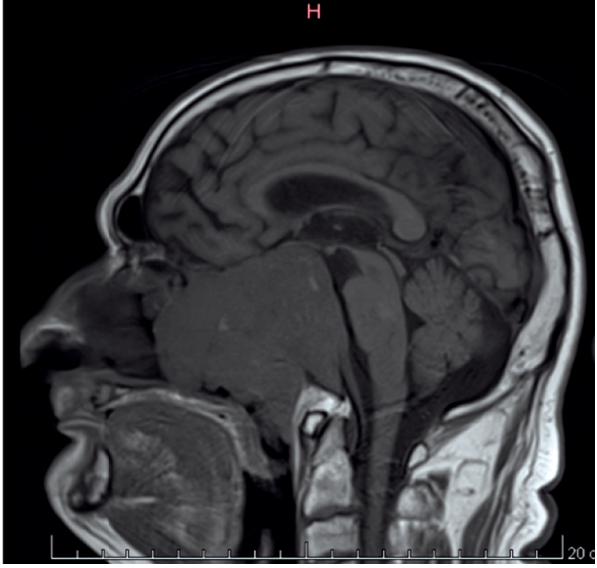

Fig. 7. MRI - T1 Sagittal Extensive anterior posterior development of recurrence
Meningiomas may reach considerable size before causing symptoms, as they are most often slowly growing tumours. Visual deterioration and headaches are the most common presentation ${ }^{2}$. Involving the nasal fossae or sinuses, meningioma may lead to nasal obstruction, epistaxis, smell disturbances, secondary inflammatory changes and even CSF rhinorrhoea ${ }^{6}$.

Contrast-enhanced computed tomography (CT) and MRI are standard radiological techniques for diagnosis, postoperative evaluation, and follow-up. On CT scan, meningioma is typically iso-dense to slightly hyper dense, homogeneous, and sharply emarginated, with marked enhancement after injection of contrast medium. Peritumoral oedema and calcifications may be variably present. Bony involvement and bony landmarks can be assessed by bone windows. Characteristic MRI features are intensity to slight hypo intensity on T1-weighted images; the appearance on T2- weighted images is variable, the presence of hyperintensity may indicate a softer tumour. Post-gadolinium enhanced images show a homogenous, usually intense mass, with or without a dural „tail“ ${ }^{2,7,8}$.

Preoperative embolization may be a useful toll in selected cases, but it is rarely required and involves considerable associated risks ${ }^{1,2}$.

Morbidity and mortality may be reduced in time by advances in neurosurgical techniques and extended/ expanded endoscopic endonasal skull base approaches. Surgical treatment is the primary treatment option for symptomatic lesions, that have a good long-term prognosis after treatment. Although meningiomas present a five-year survival of more than $90 \%$, they may recur even after total removal ${ }^{2}$. Other treatment options involve observation for asymptomatic, small lesions, and stereotactic radiosurgery ${ }^{9-11}$.

Resection of meningiomas is linked to their extension and it is according to Simpson's classification:

Grade I, total tumour removal with excision of dural attachment and abnormal bone.

- Grade II, total tumour removal and coagulation of dural attachment.

- Grade III, gross total removal without resection or coagulation of dural attachment or extradural extensions.

- Grade IV, partial removal, leaving tumour in situ.

- Grade V, simple decompression (biopsy).

A Simpson grade I or II resection is the goal, recurrence after gross total removal occurred in 9 to $15 \%^{2}$.

Standard surgical approaches for the skull base tumours differ according to tumour location, size and extension. The main concerns are postsurgical nerve palsies or risk of carotid artery (or perforating arteries) injury².

Endoscopic endonasal resection of skull base meningioma, by approaching the tumour from below, without brain retraction and minimizing the manipulation of neurovascular structures, is very attractive. Surgical limits for endoscopic approach of anterior skull base meningioma are summarised in Table $1^{2}$.

Modular classification of approaches, divided into the midline sagittal (rostro-caudal axis) and paramedian (coronal plane), has been reported. These 
Table 1. Surgical limits for endoscopic approach of anterior skull base meningioma ${ }^{2}$

\begin{tabular}{cc}
\hline Anatomic site & Limit \\
\hline Sagittal plane & $\begin{array}{c}\text { Posterior wall of frontal sinus } \rightarrow \text { cranial - cervical junction } \\
\& \text { anterior portion of the foramen magnum } \\
\text { Caudal: odontoid process }\end{array}$ \\
\hline Lateral anterior skull base & Optic nerves $\rightarrow>$ outside of superior rectus muscle bilaterally \\
\hline
\end{tabular}

extended/expanded approaches include the parasellar, the transplanum/transtuberculum, the transcribriform, the lateral approaches to the petrous apex and the approach to the anterior portion of the foramen magnum and the craniocervical junction ${ }^{12}$.

If endoscopic resection is achievable (tuberculum sellae meningiomas are most often treated in this way), literature data report a similar percentage of resection by transcranial approach and endoscopic approach. Complication rate varies from transient visual deterioration (63\%), diabetes insipidus (transient or permanent) (depending on location), pan hypopituitarism, arteries injuries, pneumocrania, intraoperative bleeding, CSF infection and CSF leaks, with difficult repairing techniques ${ }^{2,13-15}$. Quality of life is mainly affected due to permanent cranial nerve dysfunction, with a long-term impact. The European position paper on endoscopic endonasal management of endonasal tumours suggests that lesions located lateral to cranial nerves are often best suited for lateral conventional approaches, meanwhile those that are medial to the cranial nerves can be treated by endonasal approaches ${ }^{2}$. Nevertheless, both ways may be used simultaneously, with clear benefits for the patient.

\section{Conclusions}

Endoscopic approach of skull base is still an experimental field, as not all tumours are suitable for this approach and it requires experienced multidisciplinary teams. If the main complication is CSF leak, the advantage is the protection of cranial nerves, neural and vascular structures, by approaching the lesions from the base. This case report highlights that the close follow-up of these benign tumours should be done, as they may present a high rate of recurrence, with extensive development.

\section{Author Contributions:}

S.V.G.B and R.G were responsible for the diagnostic procedures, clinical diagnosis, and treatment decisions. P.L.B, M.C.C, G.S.M, S-A.C.B. and A.C. wrote the manuscript. All authors have read and agreed to the published version of the manuscript.

\section{Compliance with Ethics Requirements:}

"The authors declare no conflict of interest regarding this article"

"The authors declare that all the procedures and experiments of this study respect the ethical standards in the Helsinki Declaration of 1975, as revised in 2008(5), as well as the national law. Informed consent was obtained from the patient included in the study"

"No funding for this study"

\section{Acknowledgements:}

None

\section{References}

1. Flint PW, Haughey BH, Lund VJ, Niparko JK, Richardson MA, Robbins K. Cummings Otolaryngology - Head and Neck Surgery. $6^{\text {th }}$ ed. Philadelphia: Elesevier; 2015;674:2098-2108.

2. Lund V, Stammberger H, Piero Nicolai PC. European Position Paper on Endoscopic Management of Tumours. Rhinol-Official J Int Eur Rhinol Soc. 2010; 22:1-143.

3. Ghosh A, Ghartimagar G, Thapa S, Shrestha MK, Talwar OP. Primary nasal meningioma - a case report. J Pathol Nepal. 2017; 7:1127-9.

4. Yang XH. An ectopic meningioma in nasal floor. $J$ Craniofac Surg. 2015;26(2): e88-90.

5. Pacheco Compaña FJ, Midon Míguez J, Avellaneda Oviedo EM, Busto Lodeiro E. Post-traumatic cutaneous meningioma. Arch Plast Surg. 2016;43(4):381-4.

6. Kapitanov DN. Endoscopic endonasal diagnosis and treatment of skull base meningoencephalocele. Vopr Neirokhir. 2017;81-3.

7. Shrestha D, Liang F, Gyanwali B. Olfactory groove meningioma extension to paranasal sinus and nasal cavity: combined approach by unilateral sub frontal and endoscopic endonasal. Open Access Libr J. 2015; 2:1-5.

8. Mnejja M, Hammami B, Bougacha L, et al. Le méningiome primitif nasosinusien. Ann Françaises d'Oto-Rhino-Laryngologie Pathol Cervico-faciale. 2012;129:56-9.

9. Drummond KJ, Zhu JJ, Black PM. Meningiomas: updating basic science, management, and outcome. Neurologist. 2004;10(3):113-30.

10. Whittle IR, Smith C, Navoo P, Collie D. Meningiomas. Lancet. 2004;363(9420):1535-43.

11. Rockhill J, Mrugala M, Chamberlain MC. Intracranial meningiomas: an overview of diagnosis and treatment. Neurosurg Focus. 2007;23(4).

12. Cavallo LM, Cappabianca P, Galzio R, Iaconetta G, de Divitiis E, Tschabitscher M. Endoscopic trans-nasal 
approach to the cavernous sinus versus transcranial route: anatomic study. Neurosurgery. 2005;19(1):E4.

13. Avinash V, Mantravadi KCW. Repair of cerebrospinal fluid leak and encephalocele of the cribriform plate. In: Atlas of Endoscopic Sinus and Skull Base Surgery. $2^{\text {nd }}$ ed. Elsevier; 2019:223-32.
14. Diaconu CC, Dediu GN, Iancu MA. Drug-induced arterial hypertension, a frequently ignored cause of secondary hypertension: a review. Acta Cardiologica. 2018;73(6):511-517.

15. Bungau SG, Abdel-Daim MM, Tit DM, et al. Health benefits of polyphenols and carotenoids in age-related eye diseases. Oxidative Medicine and Cellular Longevity. 2019: 2019:ID 9783429. 